Submitted version of Price, O., Boud, D. and Scheeres, H. (2012). Creating work: employee-driven innovation through work practice reconstruction. In Bonnafous-Boucher, M., Hasse, C. Høyrup, S., Lotz, M. and Møller, K. (Eds.) Employee-driven Innovation: A New Approach to Innovation. London: Palgrave Macmillan, 77-91.

\title{
Creating work: employee-driven innovation through work practice reconstruction
}

\author{
Oriana Milani Price, David Boud, and Hermine Scheeres \\ University of Technology, Sydney
}

Considerations of employee-driven innovation generally posit innovation as an advance in the substantive products, services and/or processes of an organisation. More broadly, innovation can also refer to anything that seeks to do something new, or address a concern that would not otherwise be met. Employees contribute to innovation in many ways: they can generate and/or implement a product or service; they can generate and/or implement new technologies; however, they can also influence the ways in which an organisation adapts and evolves over time in more subtle ways through instigating work practice changes. Although these more subtle changes may not appear under the banner of organisational innovation they nevertheless contribute to the creation and application of new organisational processes, practices and outputs. They may also never be part of the conscious and explicit agenda of the organisation or be something that managers have a strong role in initiating. However, their effects can be cumulative and substantial.

Over the past few decades the relationship between workers and organisations has shifted dramatically. This shift has been underpinned not only by changes in work (e.g. service work, knowledge work) but also in the nature of organisations (e.g. flatter structures, greater autonomy, less formalisation, joint ventures to serve global markets). Similarly, contemporary workers not only expect to take responsibility for their own learning, development and careers, they can also expect to take responsibility and ownership for work activities not defined by their organisations or bound to the jobs they were employed to do. We maintain that these changes in the worker-organisation relationship and in the nature of work and organisations can open up possibilities for workers to be self-directed and creative - spaces are created where innovation can arise, albeit within certain constraints. We take the view here that innovation arises from the everyday cultural practices of workers - the ways workers enact their jobs, interact with each other and seek to become fuller members of their organisations. It occurs through workers finding ways of meeting their own interests and desires as well as those of their employers.

The focus of this chapter is on how particular forms of employee-driven innovation reconstruct employees' work and organisational practices. It illustrates practices that were not initiated with the goal of innovation in mind, but which have this as a central outcome. It draws on a wider study undertaken in different kinds of Australian organisations of what we termed integrated development practices (IDPs). IDPs are organisational practices whose primary function is the enhancement of organisational effectiveness (Chappell et al. 2009, p. 359), but also have a developmental (learning) role. They include practices such as performance appraisal, project work and teamwork. They are practices that facilitate learning, are embedded in work processes, are independent of formal training programs and are not defined explicitly in terms of training and/or education. They are typically managed or implemented by those whose primary job function is not training and learning. Thus they are not commonly driven by either an explicit learning intention, or with any explicit intention 
of innovation.

While many IDPs are familiar and much discussed, others emerged in interviews and observations during our empirical studies. The chapter explores one of the unexpected practices encountered. Recognition of it emerged during fieldwork and interviews and we termed it 're-making one's job'. We identified this as a practice in which employees reinvented themselves and their work and enacted this new work in formally reworked jobs in response to their understanding of their employer organisation and its changing needs. The chapter examines the dynamics of the processes involved and relates them to the learning of individuals and the organisation. These are discussed in terms of the circumstances that afford such possibilities of development and how they can be understood as constituting employee-driven innovation.

We begin by introducing changing ideas about what constitutes innovation and how these changing ideas have brought to the fore the emergence of the concept of employee-driven innovation. Next, we introduce the Schatzkian perspective on practice theory that we have been using to conceptualise our studies and discuss how such notions of practice can frame possibilities for change in organisations. We then introduce a range of employees in two organisations we have studied and exemplify how their practices and what they have taken up from the possibilities of their daily work has created and shaped innovation. Following discussion of how this occurs we reflect on features of organisations that sustain such innovations.

\section{Innovation and the nature of work}

Innovation in relation to work and organisations has been discussed and studied in many different ways. Early understandings of this concept were sustained by an economic focus, where innovation was something new that enabled the creation of value (Schumpeter 1934). More recent understandings focus on innovation as an organisational process critical for organisational survival: "the only way a business can hope to prosper, if not survive, is to innovate ... to convert change into opportunities... this requires that innovation itself be organised as a systematic activity" (Drucker 1994, p.1) or a process that can be managed. For example Baumol (2002) describes innovation as "the recognition of opportunities for profitable change and the pursuit of those opportunities all the way through to their adoption in practice" (p. 10). Understanding innovation not only focuses on unpacking what is meant by value beyond economic benefit, but also on understanding the processes involved in its production (see for example Sundbo, 2003 on strategic innovation; Sundbo \& Gallouj, 2000 on loosely coupled systems; Francis \& Bessant, 2005 on the 4PModel).

Much research relating to innovation as an organisational process has investigated innovations in the context of research and development (R\&D) functions within organisations (Høyrup 2010). This focus has concentrated on the section of an organisation charged with innovation and change as its raison d'être. As such, the focus is on a management-driven view of innovation. Research into innovation that has emerged elsewhere in an organisation, from employees themselves whatever their primary job function, has not been as widely explored. The concept of employee-driven innovation as it is termed, is, however, becoming more widely recognised and examined. As has been discussed earlier in this volume, according to Høyrup (2010), employee-driven innovation has a: 
"focus on innovative practices contributed by any employee (outside the boundaries of his/her primary job responsibilities) at all levels of the organisation... the innovative ideas are embedded in employees' daily work activities - often in working teams-on the basis of their experience and onthe-job training" (p.149)

Employee-driven innovation begins at the job and worker level and is a bottom-up process that may result in either radical or incremental innovation for products, services, process or markets. Sustaining employee-driven innovation are other organisational processes and managerial activities (Høyrup 2010). These may include employee suggestion and participation systems, quality improvement approaches or innovative cultural approaches (Teglborg-Lefèvre 2010). Employeedriven innovation may be conceptualised in terms of a number of elements including: content (what is new); pace (incremental or radical); recipients (new for whom); value (what is the benefit); process (how it comes about) and drivers (expertise, ideas) (Høyrup 2010).

It is employee-driven innovation understood as embedded within daily work activities of job enactment that we focus on here. Following Fenwick's (2003) idea of innovation as a form of 'everyday practice learning', we argue that employee-driven innovation embedded within daily work activities of workers' jobs emerges through their enactments and re-enactments of their jobs. Enactment comprises more than activity or physical 'doings'. To explicate what is meant here by enactment and demonstrate how it occurs and generates innovations, we employ a particular perspective on practice theory. We use this approach to illuminate the ways in which workers enact their jobs and how, in doing so, they can drive innovation within an organisation. Practice, we maintain, represents a meso level of analysis that connects individuals and organisation in a mutually constitutive relationship. The notion of 'practice' links the substance of work with the processes involved and with the person engaged in the work. It encompasses the person, the activity and the purpose.

Conventionally, jobs have been understood as reflecting pre-defined roles and tasks nested in an organisation's hierarchical configuration and described in documents such as organisational (divisional and workgroup) structure charts, job descriptions, workflows, policies and procedures (Clegg 1990; Morgeson, Dierdorff \& Hmurovic 2010; Oldham \& Hackman 2010; Rhodes \& Price 2011). This tradition continues in organisations today: workers are recruited, managed and assessed in terms of formally defined roles and responsibilities outlined in organisational documents such as job descriptions, procedures and performance plans (Robbins et al. 2010).

Operating parallel to, and sometimes almost contradicting, these formalised approaches to workers and their work, are more informal, everyday ways in which workers think about, construct and reconstruct their work. The survival of contemporary organisations in a rapidly and constantly changing environment demands workers able to envisage and incorporate ongoing change. In this sense all workers are now knowledge workers (Drucker 1994). They need to understand the whole organisation and how they can move beyond the work that has been described and itemised in texts and by managers. Consequently, many of today's workers have greater de facto input into the content of their jobs as well as "considerable latitude to customize...their jobs [make]...changes in the structure and content of jobs...[Employees] do not necessarily have to wait for managers to take the initiative" (Oldham \& Hackman, p. 470). Workers are expected to take greater responsibility and ownership of their work (Child \& McGrath 2001; Grant et al. 2010; Morgeson, Dierdorff \& Hmurovic 2010; Oldham \& Hackman 2010) if they are to 
survive and flourish in these environments, and if the organisation is to be effective. This can be understood as a kind of creative involvement in the organisation and thus can position workers as drivers of innovation.

\section{A practice approach}

We have used Schatzki's $(1996 ; 2002 ; 2001)$ theorisations of practice as they have proved fruitful in our previous research (eg. Price, Scheeres \& Boud 2009) in understanding what workers do at work. It has enabled us to avoid unhelpful polarisations between individual and organisation, and learning and work. His framework of what constitutes practices brings together notions of worker, context, relationships and tasks as a means of understanding how workers enact their jobs and at the same time reshape those jobs and the practices of their organisations. In his understanding of organisations as "bundles of practices and material arrangements" (p. 1863) - as a nexus of existing and altered practices which entwine people, technology and spaces where practices occur - Schatzki recognises that practices frame past, present and future possibilities. Workers enact organisational practices through participation in their jobs and the organisation itself. An integral part of the enactment of organisational practices and workers' jobs involves workers drawing on their "practical intelligibility" (Schatzki 2002, p. 74). That is, they draw on their understandings of the practices of the organisation and they carry out at least some of the activities (doings and sayings) associated with those practices.

While workers' understanding and enactment of practices within a particular organisational context ensures the perpetuation of the organisation and its practices, this acceptance does not mean that workers are determined by these practices. Whether consciously or unconsciously, as they enact organisational practices workers draw on their practical intelligibility to carry practices forward and at the same time vary them, enmeshing elements of existing practices with previous understandings of similar practices from other contexts (e.g. previous jobs, prior experiences or knowledge) (Price, Scheeres \& Boud 2009; Schatzki 2006). It is through this process of enmeshment of practices that we understand how employeedriven innovations emerge. Workers, as participants in organisations, are active coconstructors and innovators of work and jobs.

\section{Employee-driven innovation through re-making one's job}

In highlighting the ways in which workers enact their jobs and at the same time innovate within contemporary organisations we draw on a recent research study. In particular, we utilise data from two Australian workplaces in the public sector: a local government (henceforth the Council) and a public utility (henceforth the Utility). Council is a local government council in a large metropolitan area. Australian councils represent the third layer of government and are responsible for the provision of services (e.g. libraries, road maintenance, waste collection, building development assessments) and governance at a local community level. The Council has a hierarchical structure, which includes the elected Council, Mayor, a General Manager, Group Managers, Managers, Team Leaders and six hundred employees. Utility is an incorporated government public utility organisation that provides electricity distribution to parts of the state of New South Wales. Utility has a hierarchical structure that includes a State Minister, Board of Directors, Chief Executive Officer, General Managers, Regional Managers and two thousand employees. Our study was conducted in a region of Utility that employs three hundred employees. 
Council and Utility are organisations that have experienced periods of significant change as a result of policy changes at the State (NSW State Government New Public Management Policy) and Commonwealth (National Competition Policy) government levels. For the Council these changes resulted in new modes of operation. These included greater accountability at the local community level, greater efficiencies in service delivery and resource management and the adoption of the principles of competition and market contestability. For Utility, the application of New Public Management policies, coupled with deregulation and the establishment of a national utility market, significantly shifted the dynamics of this industry. For Utility this meant a significant shift in its structures and modes of operations.

The research methods of our project included semi-structured interviews, observations and analysis of organisational documents. Thirty interviews were conducted with workers across hierarchical levels and functions of each organisation. We carried out approximately 10 hours of observation of work practices. The organisational documents we analysed included annual reports, business plans, policies and procedures and job descriptions from both organisations. The interviews focused on the re-told experiences of workers as they enacted and extended a number of organisational practices pertaining to their jobs. The document analysis provided formalised descriptions of these organisations and enabled us to understand the organisational practices and the jobs within them. The data generated from these methods enabled various accounts of practice and jobs to emerge. Observations of the worksites and work practices allowed us to further understand the work of the organisations and of the work and worker practices. They gave us a 'feel' for each workplace.

Workers in the study enacted the practices of their organisations through their jobs and at the same time they were changing the practices of their own jobs and their organisations' practices. The workers at Council and Utility talked about how in the enactment of their jobs, they varied those jobs and the practices inherent in them we named this practice re-making of one's job. Workers in both organisations remade their jobs by drawing on knowledge, experience and understandings - their practical intelligibility and readings of their changing organisational circumstances. An important feature was that workers sometimes also re-made the practices of their organisations. It is this re-making of jobs and organisational practices that may be understood as employee-driven innovation.

To illustrate this re-making, we focus on five employees. Guy and Sally had been with Council for over fifteen years and Stan had been with them for less than a year. Miles and Harry are two workers that had been employed by Utility for over ten years.

Guy told us that in undertaking his job as Manager, Library and Community Services he drew on his previous work experience in local government in general, and his specific experiences as a Civil Engineer at Council. Guy told of how he re-made his job by undertaking an entrepreneurial approach to community services:

"I manage what is called community development and services - there's a planning policy type area of the unit and there's also service delivery which is the library and also meals on wheels service, immunisation service [before I came to this job] ... I didn't know a lot [about libraries or community services] but I was active participating in projects that involved [libraries and community 
services] areas ... it was as a given in the engineering areas [where I worked] that you only had to put up a technically difficult report to get the most money - because no one could understand it ... I could see the struggle that was happening in the [libraries and community services] areas and I thought how do I move the pot hole to the library or to community development? So I took up that challenge... how do I move that pot hole to the library - I used a similar analogy to try and achieve better resources [Library and Community Services Manager].

In describing his early experiences as the Manager, Library and Community Services, Guy went on to say:

... I knew it was going to be difficult ... it's more difficult to equate the value of a project of wellbeing of the community or the value that a library may bring to a family over 50 years ... [as opposed to a road] and that's always been a toughie to win in terms of traditional senior management structure that if they're economic rationalists ... the social entrepreneur [is] really about my view on how I can build a stronger community development area through some entrepreneurial approaches - like moving the pot hole to the library l've worked with some of the private donation organisations to get some programs up in [this area]".

For Guy "like moving the pot hole to the library" has meant re-making the traditional job of a Manager, Library and Community Services to have a greater focus on talking up the library as a community asset, of bringing to the fore new ways of demonstrating to the "economic rationalists" its value to the organisation. Similarly, in utilising "entrepreneurial approaches" and networking with philanthropic organisations from Sydney's wealthier suburbs, Guy told us of how he was able to access private donations to fund, for example, for a senior women community group "... well 10 grand [\$10,000] just came along straight up".

In re-making his Manager, Library and Community Services job to have an entrepreneurial approach, Guy was innovating. He was able to create a new way in which the organisation could understand the function and role of the library and community services division. Further, in identifying new sources of sponsorship and support for the provision of services to community groups, he was also creating new economic value for the Council and its community.

Sally, who had worked with Council for about eighteen years talked about having been part of the Council when it initiated its commercial practices. She told us of how she re-made her job of Policy Analyst, from having a narrow focus on "developing strategies and policies" to a broader organisational focus of managing the process for developing Council's overall management plan:

"My job title is policy analyst but I have become specialised in creating, developing and producing council's management plan which is [Council's] strategic and operational plan for the future, the strategies which runs about 5 years into the future and the operational runs about 12 months ahead ... my main focus is the management plan [process] and what goes into developing it and that includes some heavy consultation, some management workshops, some councillor workshops ... the sorts of things you might do in strategic planning and sometimes in change management as well ... sort of a aligning the vision and the council's strategies and actions with what's getting done day to day ..." 
In re-making her job to manage Council's management planning process, Sally moved beyond Council's previous practices of management planning which encompassed:

"... just putting a document together [and telling the operational areas] this is our plan based on the budget, you get the budget and you can see the actions in it and that's what we're going to do and there you have your plan".

Sally focused on developing the management planning practices to encompass internal and external consultation. Sally told how her re-made job is about:

"building relationships with the departments and the managers who have to implement the action plans that the management plan represents and that means that there's a lot of formal and informal relationship building going and the informal part ... the sort of work that you need to do to that isn't always part of your job description ... it is the team building stuff you might have and the sorts of meetings that you might have that you do work ancillary ... that gives a little bit of relationship building ... certainly facilitation ... negotiate ... manage conflict when there's different priorities and managers are really stressing out about their things and they want them to get done and in the budget".

In re-making her job and the organisational practices of management planning, Sally was innovating. In terms of the broader context of innovation, Sally had not only reconstructed organisational practices relating to the preparation of the strategic planning document, she also reconstructed the practices of managers involved in this organisational process.

At the Council, existing workers were not the only workers who were innovating. Stan, a newly employed Parking Patrol Ranger, also talked about this practice. In outlining the elements of his job, Stan told of how he was responsible for issuing parking infringement notices when drivers were parking contrary to Council parking regulations. However, Stan approached his job differently, he understood his job as:

“... not so much giving people tickets, I think for me it's enforcement by presence, I think it made a big difference. I found you can get a lot more people to start doing the proper thing, not so much [by] coerc[ing] them but [by saying to them] 'listen, you can't be here'. They'll go, 'yeah' [because] they don't want a ticket no more than I would want to give people tickets ... the people that l've told to move on, they remembered it so the next time".

Not unlike Guy and Sally, Stan has also been innovating within the general scope of his position. In taking a community education focus to parking patrol, Stan has been taking a creative approach in the enforcement of Council's parking patrol regulations - he is changing organisational processes and practices pertaining to parking and attempting to shift community cultural values towards parking through education rather than enforcement.

At Utility workers were also innovating. Miles, a worker who had recently been appointed to a newly created role of Project Manager explained how he negotiated organisational expectations for project management and existing organisational structural barriers that prevented him from fully implementing project management practices. Miles told of how in his new role he was responsible for both the financial and technical management of projects, however his authority did not extend over the 
workers who actually carried out the construction of the projects he was responsible for. In order to address this disconnection between authority and responsibility over projects, Miles re-made his job to have a greater focus on relationships:

"I don't have anyone that directly reports to me ... [the construction crews report to the Operational Managers who are in a different group]. I can't demand anything, I can only ever ask ... I find that I've got to try and foster relationships ... [the construction crews and their managers, the Operations Managers] are key players in the measurement of my output, so I've got to make sure that there is a good relationship between us ... that I deal with in those areas well, and understand what their concerns are, if they come to me with a query about some jobs or I need something shoved into the [Construction] programme, having that good relationship helps".

In the re-making of his job to have more of a relationship focus, Miles has been innovating the ways in which project management practices could be executed in the context of the Utility - in a context where project responsibility and authority over project resources remained separate. Through his innovative approach, Miles attempted to shift elements of an 'us and them' mentality between the project managers and the construction crews. He reconstructed new organisational practices in order to achieve his own and the organisation's asset management outcomes.

Harry a worker in the same department as Miles described his job as "Everything Man", a job that:

"changes everyday... it's the sort of position you probably put two different people in and you get two very different outcomes ... [when I first started] it was just purely feeling your way through ... just listened to what everyone was whinging and complaining about [and then I decided to] try and fix one [problem] first ... and as you fix one problem, everyone goes oh you fixed that, oh, have a go at this, have a go at that ... it's got to the stage where a lot of people now come to me now when they want the process improved, or they want something fixed ..."

Harry went on to tell us that part of his job was also to fill in when other members of his team went on leave:

“... I am able to slot in [and do other jobs] when people take leave, I find while I'm doing their job, instead of just watching someone doing it, [I think there's got to be] a better way ... [I put] it in the back of my mind and it goes on my little list [of things to fix] and whenever I get bored, l'll pull that one out and work on [it] ... [for example when], the customer services manager left, I virtually slotted into [the] role, which l'd never done before, it was just like, argh ... the recording of all the jobs was very old fashioned, manual filing, no linkages, duplication ... all manual input, and then, the end of the month, month reporting, it was reading through it and then typing it into another one, and paper files ... I went off and rewrote the entire spreadsheet, macros, programming behind it. So basically they're all linked now, so come the end of the month, it doesn't matter where it is, it's one click and you've got your instant figures. Same as you've got an instant report of where everything's up to, every job that's happened".

In his approach to his mostly undefined job, Harry has been creating and fulfilling opportunities for innovation. By being able to step into different roles on a temporary basis, Harry has been able to develop a comprehensive understanding of the 
different jobs within his department and the interrelationships among them. In seeking out and fixing problems, Harry was reconstructing processes and practices and generating new and innovative ways to execute work within his department.

What can be seen from the accounts of everyday work provided by Guy, Sally, Stan, Miles and Harry is that these workers have been drawing on their practical intelligibility, their expertise, knowledge and skills to drive new approaches within their organisations. These workers were, in Schatzki's terms, enacting practices that, at the same time perpetuated and changed existing organisational practices. They added value to their organisations in various ways, by reconstructing practices and processes, shifting elements of work culture or creating new understandings about the ways in which work could be executed - these workers were innovating in and through their day-to-day work.

While these innovations could from other perspectives be read as examples of individual creativity - they clearly show initiative and personal agency-they arise through more complex convergences and interactions. Innovations need individuals to realise affordances of their work, but they also require the practices of work to provide such affordances. Different kinds of organisation and different development practices within them may not provide the possibilities of emergence of innovation.

\section{Sustaining worker innovation}

Discourses of change and innovation are heard in the corridors and meeting rooms of all contemporary organisations. Rapid shifts in modes of communication and technologies of all kinds have led to reconceptualisations of what it is to be an organisation, what constitutes work, and what it means to be a worker. Organisations can no longer be understood as entities that devise and implement ways of working that persist with adjustments now and again, carried out by workers who come with readymade skills and expertise. Paradoxically, organisational stability incorporates ongoing change, and all employees are expected to be involved in the business of organising. This involvement includes a shift to greater worker responsibility and trust, rather than control by managers (Child \& McGrath 2001; Drucker 1994). A structural view of organisations as having fixed arrangements between workers of different kinds and levels is being displaced by one in which, while the imprint of the structure remains, it is continually troubled by a re-working of boundaries and relationships, formally and informally.

Within the organisations discussed here, work occurred in contexts where change had been a key feature. These organisations had gone through periods where goals, values and modes of operating had been significantly reframed. Inherent in these new modes of operation were tensions and gaps between new and old ways of doing things - old ways did not quite fit and new ways were not sufficiently developed to achieve the new organisational imperatives. The context of these organisations were such that workers were afforded the freedom (and perhaps expected) to become the architects in building bridges to fill these gaps, in finding ways to smooth the tensions - these workers were afforded the opportunity to innovate through their everyday work.

As organisations are looking to their employees as trusted organisational members who contribute new ideas and processes, the issue of how to draw employees to this worker and organisational identity, and how to sustain both the generation of innovations and the innovations themselves, is paramount. In the organisations we investigated, we found that employees were able to 're-make' their jobs in an atmosphere in which it was legitimate to do so. They went about creating their jobs 
bringing together existing and new organisational practices. In line with Schatzki (2006) these employees were carrying organisational practices forward and at the same time varying those practices in ways that accommodated the situation in which they found themselves. They were able to do so because their organisations valued the outcomes of such innovation and permitted, even encouraged, employees to act accordingly. This is in contrast to older forms of organisations in which fixed or hierarchical relationships are privileged and employees are valued for doing well within their existing job description.

Learning is a necessary and important feature of this kind of innovation, but it is not useful to conceptualise it in ways familiar from education and training. It utilises everyday learning at work and can be seen as a form of learning in-between, that is in a third space that is neither personal/social space, nor work space, but a hybrid that draws on discourses of both to be productive. This is learning that occurs between "on-the-job and off-the job" standing between the formal areas of practice and informal areas of interaction (Solomon, Boud \& Rooney 2006, p. 11). Hulme, Cracknell \& Owens (2009, p.541) suggest that this hybridity pertains to the integration of competing knowledges and discourses; to the reading and writing of subject matter and to the individual and social spaces, contexts and relationships.

Learning is implicated in re-making practices, but there is no direct correspondence between particular kinds and ways of learning and innovation as such. Employee-led innovation occurs through a conjunction of circumstances and the ability of employees to respond to and utilise the opportunities that occur in work. It is not susceptible to being planned by some agent other than those involved. It may best seen as an emergent practice in which 'learning develops as a collective generative endeavour from changing patterns of interactional understandings with others' (Johnsson \& Boud 2010). That is,

"how workers take up ... opportunities result[s] from a complex combination of situational factors that generate invitational patterns signalled from and by various understandings and interactions among actors doing collective work." (p. 359)

We suggest that it was the openness of job descriptions, and the ongoing context of change that enabled these workers to enact their jobs in different ways - they knew change was expected, but what it was and how it could be implemented was open to creative ideas. These expectations and allowances, together with the ways in which Guy, Sally, Stan, Miles and Harry brought understandings of practice perpetuation and change to their jobs provided a fertile context for generating innovation. We conclude that it is a coming together of individuals and organisational practices involving the aspirations of individuals to be part of the organisation in ways that are linked more strongly into their desires and interests than the jobs to which they were originally appointed that is implicated in employee driven innovations. It is these kinds of organisational contexts and approaches to work where there is a sense of ownership engendered, rather than a management-devised directive, that we see here helping to drive and sustain innovation.

This chapter has focused on one of the Integrated Development Practices that we identified as part of our wider study. We have chosen to report on this example as it was particularly generative of employee-led innovation. However, it is possible to identify other IDPs in the selected organisations as also generating employee-led innovation, albeit less immediately obvious in their impact. This leads us to suggest that a focus on the practices of organisations and their members is likely to be a fruitful source of innovation data. Such micro-analysis of organisational life 
illuminates many features that can be obscured in more normative or larger-scale analyses.

\section{Conclusions}

Unlike Fenwick (2003) who identified innovation in new enterprises, we have seen substantial employee-led innovation at the everyday practice level in mature organisations. We have identified an interesting set of innovation practices, which is necessarily employee-led. It is one that does not depend on the particular characteristics of an entrepreneurial individual or group, nor on altruistic motives in improving the organisation. It works through the desire of people to work in ways that satisfy themselves and to effectively meet the needs of whatever kind of work they are involved in. They necessarily utilise existing organisational practices and affordances to do this in similar ways that they need to use them for other aspects of their work. These development practices may have been created by organisations for quite different purposes-like job descriptions to select applicants and frame employees' work-but once they exist and are seen as legitimate parts of an organisational infrastructure, they can be used for other ends, including those not foreseen by their instigators.

We have no normative intent in drawing attention to this phenomenon of emergent innovation. It is not necessarily more appropriate, nor may it result in particular kinds of innovation, neither does it necessarily lead to superior kinds of innovation: we have no data on these features and make no claims about these matters. The innovation processes we have identified are ones that cannot be established in advance, or designed into a formal innovation strategy. They are contingent on the engagement of practitioners with the particularities of their own practices and the practices they encounter in their organisation. Such engagement is an intrinsic feature of learning work, and with such engagement comes innovation. 


\section{References}

Baumol, W.J. 2002, The Free-Market Innovation Machine: Analyzing The Growth Miracle Of Capitalism, Princeton University Press, Woodstock.

Chappell, C., Scheeres, H., Boud, D. \& Rooney, D. 2009, 'Working out work: Integrated development practices in organisations'. In J Field (ed.), Researching Transitions in Lifelong Learning Routledge, London, pp. 175 188.

Child, J. \& McGrath, R.G. 2001, 'Organizations unfettered: Organizational form in an information intensive economy', Academy of Management Journal, vol. 44, no. 6, pp. 1135 - 1148.

Clegg, S.R. 1990, Modern Organizations, Sage, London.

Drucker, P.F. 1994, Post-capitalist Society, HarperCollins, New York.

Fenwick, T.J. 2003, 'Innovation: Examining workplace learning in new enterprises', Journal of Workplace Learning, vol. 15, no. 3, pp. 123-132.

Francis, D. \& Bessant, J. 2005, 'Targeting innovation and implications for capability development', Technovation, vol. 25, no. 3, pp. 171-183.

Grant, A.M., Fried, Y., Parker, S.K. \& Frese, M. 2010, 'Putting job design in context: Introduction to the special issue', Journal of Organizational Behavior, vol. 31, no. 2-3, pp. 145-157.

Hulme, R., Cracknell, D. \& Owens, A. 2009 'Learning in third spaces: developing trans-professional understanding through practitioner enquiry', Educational Action Research, vol. 17, no. 4, pp. 537-550.

Høyrup, S. 2010, 'Employee-driven innovation and workplace learning: basic concepts, approaches and themes', Transfer: European Review of Labour and Research, vol. 16, no. 2, pp. $143-154$.

Johnsson, M. \& Boud, D. 2010, 'Towards the emergent view of learning', International Journal of Lifelong Education, vol. 29, no. 3, pp. 355-368.

Morgeson, F.P., Dierdorff, E.C. \& Hmurovic, J.L. 2010, 'Work design in situ: Understanding the role of occupational and organizational context', Journal of Organizational Behavior, vol. 31, no. 2-3, pp. 351-360.

Oldham, G.R. \& Hackman, J.R. 2010, 'Not what it was and not what it will be: The future of job design research', Journal of Organizational Behavior, vol. 31, no. 2-3, pp. 463-479.

Price, O.M., Scheeres, H. \& Boud, D. 2009, 'Re-making jobs: Enacting and learning work practices', Vocations and Learning, pp. 1-18.

Rhodes, C. \& Price, O.M. 2011, 'The post-bureaucratic parasite: Contrasting narratives of organizational change in local government', Management Learning, vol. 42, no. 3, 241-260

Robbins, S.P., Judge, T.A., Millet, B. \& Jones, M. 2010, OB: The essentials, Pearson Australia, Sydney.

Schatzki, T.R. 1996, Social Practices: A Wittgensteinian approach to human activity and the social Cambridge University Press, Cambridge.

Schatzki, T.R. 2002, The site of the social: a philosophical account of the constitution of social life and change, Pennsylvania State University Press, University Park.

Schatzki, T.R. 2006, 'On organizations as they happen', Organization Studies, vol. 27, no. 12 , pp. $1863-1874$.

Schatzki, T.R., Knorr Cetina, K. \& von Savigny, E. 2001, The practice turn in contemporary theory, Routledge, London.

Schumpeter, J. 1934, The theory of economic development, Oxford University Press, Harvard MA. 
Solomon, N., Boud, D. \& Rooney, D. 2006, 'The in-between: Exposing everyday learning at work', International Journal of Lifelong Education, vol. 25, no. 1, pp. 3-13.

Sundbo, J. 2003, 'Innovation and strategic reflexivity: An evolutionary approach to applied to services', in L. Shavinina (ed.), The international handbook on innovation, Elsevier, Oxford, pp. 97-114.

Sundbo, J. \& Gallouj, F. 2000, 'Innovation as a loosely coupled system in services', International Journal of Services Technology and Management, vol. 1, no. 1, pp. 15-36.

Teglborg-Lefèvre, A. 2010, 'Modes of approach to employee-driven innovation in France: an empirical study', Transfer: European Review of Labour and Research, vol. 16, no. 2, pp. 211-226. 